\title{
Invasive ctenophore Mnemiopsis leidyi in Norway
}

\author{
AINO HOSIA ${ }^{1}$ AND TONE FALKENHAUG ${ }^{2}$ \\ ${ }^{1}$ The Natural History Collections, University Museum of Bergen, University of Bergen, Bergen, Norway, ${ }^{2}$ Institute of Marine \\ Research, Flødevigen, Norway
}

\begin{abstract}
We present data on the occurrence of the invasive ctenophore Mnemiopsis leidyi in Norway after the initial observations made in 2005. Our data comes from several net sampling investigations conducted along the Norwegian coast in 20082014, as well as beach seine bycatch from the south coast (September-October 2005-2014). In 2008-2010, M. leidyi occurred in moderate abundances $\left(\leq 0.56\right.$ lobate ind $\mathrm{m}^{-3}$ ) during autumn, with northernmost observations from Trondheimsfjord. Mnemiopsis leidyi was not observed in 2011-2012 and was scarce in 2013, but in 2014 it was again abundant along the south and west coasts. While temperature and salinity conditions along the Norwegian south coast and its fjords are sufficient for survival and reproduction by $\mathrm{M}$. leidyi, temperature may limit egg production rates. Biological factors including food limitation as well as competition and predation by native gelatinous predators can also constrain populations. Mnemiopsis leidyi populations in Norway are likely to exhibit source-sink dynamics, with advective losses and suboptimal conditions preventing overwintering in large areas along the coast. The presence of $\mathrm{M}$. leidyi in the southern North Sea, coupled with the cyclonic circulation pattern, suggests that outbreaks may nevertheless be expected in years with favourable conditions and/or significant inflow from the southern North Sea. Climate change could enhance reproduction of M. leidyi in Norway and protected inner fjords may offer a suitable habitat for establishment of local populations in the future.
\end{abstract}

Keywords: introduced species, NIS, invasive species, Norwegian Coastal Current, North Sea, fjords, temperature, metapopulation, source-sink dynamics, jellyfish, comb jellies

Submitted 5 November 2014; accepted 20 January 2015

\section{INTRDDUCTION}

The ctenophore Mnemiopsis leidyi A. Agassiz, 1865 is a successful invasive species with a bad reputation. From its native range along the temperate to subtropical Atlantic west coast, $M$. leidyi has embarked on several trans-Atlantic invasions, most likely in ballast waters. The notoriety of $M$. leidyi stems largely from its invasion of the Ponto-Caspian region towards the end of the last century. The arrival of the voracious planktivore in the Black Sea in the 1980 s coincided with, and was partly blamed for, a collapse in commercial fisheries (Kideys, 2002). It is, however, likely that concurrent environmental problems including overfishing and eutrophication contributed to both the collapsing fish stocks and the invasive success of $M$. leidyi (Daskalov et al., 2007). In the late 1990 s the ctenophore further spread to the Caspian Sea, where its predatory impact had substantial effects on the ecosystem through trophic cascades (Roohi et al., 2010).

In the beginning of the current millennium, M. leidyi spread to the North Sea and the Baltic Sea (Faasse \& Bayha, 2006; Javidpour et al., 2006; Boersma et al., 2007; Oliveira, 2007; Tendal et al., 2007; Antajan et al., 2014) in what molecular studies suggest was a separate invasion event by a more northern source population than the one established in the

Corresponding author:

A. Hosia

Emails: aino.hosia@um.uib.no; aino.hosia@gmail.com
Ponto-Caspian (Reusch et al., 2010). Simultaneously, M. leidyi has also spread to the Mediterranean, most likely through secondary invasion from the Black Sea (Ghabooli et al., 2011; Bolte et al., 2013).

The invasive success of $M$. leidyi can be attributed to a combination of ecological and life history traits conducive to the establishment of new populations. These include a wide tolerance for environmental conditions such as temperature, salinity and dissolved oxygen, opportunistic feeding with dietary flexibility and high potential ingestion rates, as well as the potential for rapid population increases due to high fecundity, short generation times and the capacity for self-fertilization (reviewed in Purcell et al., 2001; Costello et al., 2012). Abundant $M$. leidyi can have a considerable predatory impact on mesozooplankton populations (Granhag et al., 2011), with the subsequent cascading effects on the rest of the ecosystem potentially resulting in socio-economic problems, as evidenced by experiences from the Ponto-Caspian region (Knowler, 2005). The recent appearance of $M$. leidyi in new European seas has, therefore, caused public concern and prompted research on the extent and consequences of the invasions.

The first confirmed observations of M. leidyi in Norwegian waters stem from Oslofjord in 2005 (Oliveira, 2007). In 2006, M. leidyi was also observed on the west coast, outside Bergen (Hansson, 2006). Unfortunately, monitoring of M. leidyi in Norwegian waters has been inconsistent and no further observations in Norway have been published. Here, we combine and present data on M. leidyi distribution and abundance in 
Norwegian waters since the initial observations and discuss the factors influencing its spread and distribution along the Norwegian coast.

\section{MATERIALS AND METHDDS}

\section{Study area}

The study area covers the Norwegian south and west coast up to $\sim 65^{\circ} \mathrm{N}$ (Figure 1). Surface circulation along the Norwegian coast is dominated by the Norwegian Coastal Current ((NCC) salinity $\sim 25-34.5$ ) flowing first south-west and then northwards along the entire coast. The NCC originates primarily

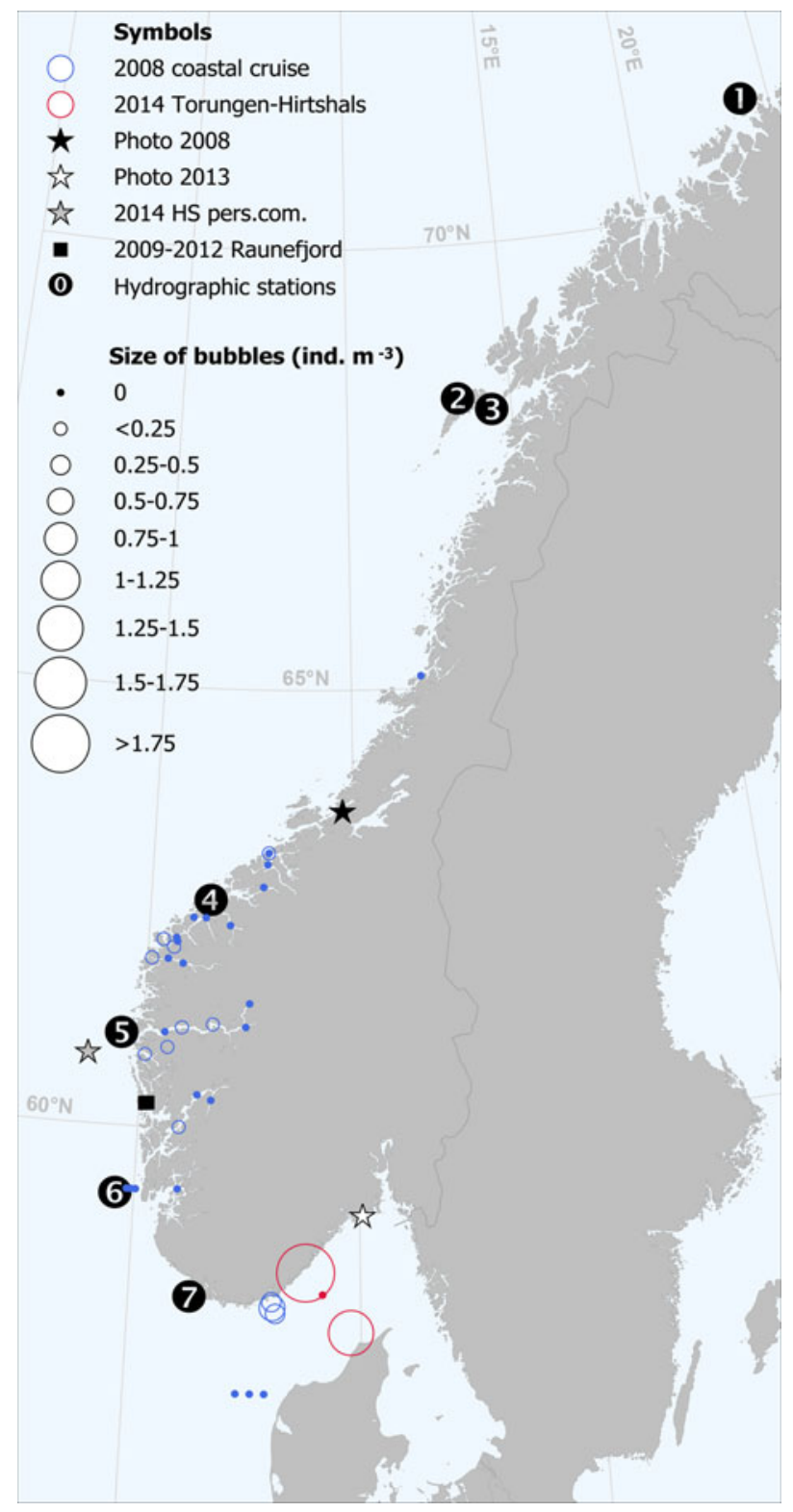

Fig. 1. Mnemiopsis leidyi observations along the Norwegian coast in November 2008 and the Torungen - Hirtshals transect in September 2014. Bubble size is relative to $M$. leidyi density. Also shown are the locations of $\mathrm{WP}_{3}$ hauls without $M$. leidyi taken during these investigations, the approximate locations of the hydrographic stations $(1=$ Ingøy, $2=$ Eggum, $3=$ Skrova, $4=$ Bud, $5=$ Sognesjø, $6=$ Indre Utsira, $7=$ Lista) and the locations of miscellaneous additional $M$. leidyi observations. from brackish outflow from the Baltic Sea through the Skagerrak, and from Norwegian fjords and rivers (Sætre, 2007; Sætre \& Aure, 2007). North Sea water contributing to the NCC is transported into the Skagerrak from the southern/central North Sea and the German Bight, and along the west coast of Denmark by the Jutland current - part of the generally cyclonic circulation in the North Sea (Sætre \& Aure, 2007). En route, the NCC is mixed with the more saline Atlantic water (salinity $>34.5-35$ ) flowing below and outside it, increasing its salinity (Sætre, 2007; Sætre \& Aure, 2007). The Norwegian coast is characterized by numerous fjords, often separated from the continental shelf outside by a sill of varying depth. Freshwater runoff to the fjords results in an estuarine circulation with a brackish surface layer, while more saline water is found in the fjord basins.

\section{Sampling}

Net sampling was conducted on the following occasions, primarily using a $\mathrm{WP}_{3}$ net (opening $1 \mathrm{~m}^{2}$ ) with vertical hauls and a towing speed of $\sim 0.3 \mathrm{~m} \mathrm{~s}^{-1}$ :

(1) In November 2008, $\mathrm{WP}_{3}$ hauls from a variable tow depth to the surface were made along the Norwegian coast up to $\sim 65^{\circ} \mathrm{N}$ during a cruise on the $\mathrm{R} / \mathrm{V}$ Håkon Mosby (Figure 1 , Table $\mathrm{S}_{1}$ from the supplementary material).

(2) From November 2009 to December 2011 and during the second half of 2012, monthly ctenophore monitoring was carried out at two stations (St 1: $60^{\circ} 16.0^{\prime} \mathrm{N} 005^{\circ} 11.6^{\prime} \mathrm{E}$, bottom depth $\sim 128 \mathrm{~m}$; St 2: $60^{\circ} 15.597^{\prime} \mathrm{N} 005^{\circ} 08.386^{\prime} \mathrm{E}$, bottom depth $\sim 244 \mathrm{~m}$ ) in Raunefjord, south of Bergen, using $\mathrm{WP}_{3}$ hauls from above the seabed to the surface (Figure 1, Table $\mathrm{S}_{1}$ ).

(3) In November 2009 and October 2010, samples were collected in Hardangerfjord, western Norway, during two cruises on the R/V Hakon Mosby as part of the Epigraph Project (Falkenhaug \& Dalpadado, 2014). Vertical hauls were made with $\mathrm{WP}_{3}, \mathrm{WP}_{2}$ and Juday nets and depth stratified, oblique hauls with MOCNESS (Multiple Opening/Closing Net and Environmental Sensing System; Wiebe et al., 1985) along a transect extending from the inner fjord area to the fjord mouth (Figure 2, Table $\mathrm{S}_{1}$ ).

(4) In September-October 2010, $\mathrm{WP}_{3}$ samples were collected in conjunction with a beach seine survey cruise on R/V G.M. Dannevig along the south-eastern coast of Norway and in Oslofjord. $\mathrm{WP}_{3}$ hauls from depths of $50 \mathrm{~m}$, or from above the seabed (when bottom depth was $<50 \mathrm{~m})$ to the surface were made at 26 stations (Figure 2, Table $\mathrm{S}_{1}$ ).

(5) In September 2014, $\mathrm{WP}_{3}$ samples were collected along the Torungen-Hirtshals transect on the R/V Håkon Mosby. $\mathrm{WP}_{3}$ hauls from depths of $50 \mathrm{~m}$ to the surface were made on three stations (Figure 1 , Table $S_{1}$ ).

Detailed information on the used gear, location, available environmental parameters and ctenophore size is provided in Table $S_{1}$. For the net samples above, ctenophores were identified, enumerated and measured from live samples directly after sampling. Ctenophore size was measured as the oral-aboral length. Only specimens from transitional stage and above are considered in the present data, as larvae may not have been adequately sampled by the nets used and 


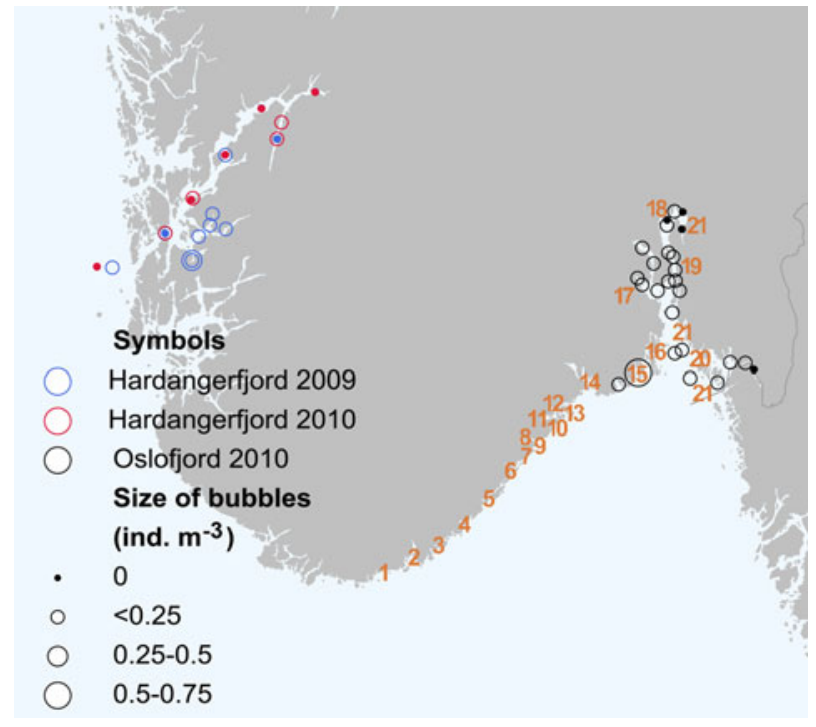

Fig. 2. Mnemiopsis leidyi observations in Hardangerfjord November 2009 and October 2010, and Olsofjord September-October 2010. Also shown are the locations of $\mathrm{WP}_{3}$ hauls without $M$. leidyi taken during these investigations. Orange numbers indicate the approximate locations of the beach seine sampling areas along the coast; note that area 21 denotes extra sites, the location of which varies from year to year.

their morphological identification to species level can be difficult. CTD casts for temperature and salinity were taken at most stations.

In addition to net sampling, an index of lobate ctenophore bycatch abundance was recorded in September-October from 2005 to 2014 during the Norwegian Skagerrak beach seine survey, an annual monitoring program for juvenile fish ongoing since 1919 (Fromentin et al., 1997; Durif et al., 2011). The sampling comprised 84-138 sites annually, grouped into 21 areas along the south-east coast of Norway (Figure 2). The following index was used for ctenophore abundance in the beach seines: $0=$ none, $1=$ one, $2=$ few, $3=$ some, $4=$ many, $5=$ very many. We have calculated annual average indices for each area.

\section{Other observations}

Some observations were also obtained by searching the web for underwater images of Mnemiopsis leidyi in Norway and soliciting help from UW photographers. Photographic documentation was required in order to exclude observations of the externally similar lobate Bolinopsis infundibulum (O.F. Müller, 1776), native along the entire coast.

\section{Prevailing environmental conditions}

To evaluate Mnemiopsis leidyi's potential for survival and reproduction in Norwegian waters, we looked at a time series of monthly average temperatures at several depths during the past $\sim 40-80$ years until 2012 at seven permanent hydrographical stations located along the coast (http://www. imr.no/forskning/forskningsdata/stasjoner/) (Figure 1). Prior to analysis, years with incomplete sampling during the period of minimum and/or maximum temperatures were manually removed from the time series. We then extracted a time series on the annual temperature minima and maxima for each station, to compare with $M$. leidyi's temperature requirements for survival and reproduction, obtained from literature.

\section{Presentation of data}

Figures were prepared using R version 2.15.3 (R Core Team, 2013) and Manifold System 8.o.

\section{RESULTS}

\section{Net sampling}

During the cruise in November 2008, Mnemiopsis leidyi were encountered at several locations along the south and west coasts, with the northernmost individuals sampled at Sunndalsfjord (Figure 1, Table $\mathrm{S}_{1}$ ). The highest concentrations, 0.54 ind $\mathrm{m}^{-3}$ in the upper $50 \mathrm{~m}$, were encountered in the south, close to Oksøy. In the west coast fjords, the abundance of $M$. leidyi was greatest towards the mouth of the fjord, with the species mostly absent from the inner fjords.

In Raunefjord, Mnemiopsis leidyi were observed during the first sampling efforts in November 2009, as well as in October-Novemver 2010 (Figure 3, Table S1). No M. leidyi were observed during sampling in 2011 or 2012. The highest abundance ( 0.1 ind $\mathrm{m}^{-3}$ in the upper $100 \mathrm{~m}$ ) was recorded in November 2009. Other ctenophores commonly observed during the sampling included Bolinopsis infundibulum, Pleurobrachia pileus (O.F. Müller, 1776) and Beroe cucumis Fabricius, 1780 (Figure 3).

In Hardangerfjord, M. leidyi was recorded at eight out of 27 stations in November 2009, and at four out of 24 stations in October 2010. Abundances were generally higher in November $2009\left(\leq 0.40\right.$ ind $\left.\mathrm{m}^{-3}\right)$ than in October 2010 $\left(<0.2\right.$ ind $\left.\mathrm{m}^{-3}\right)$. The highest concentrations were found in the outer fjord area, and in one of the fjord branches (Figure 2, Table $\mathrm{S}_{1}$ ). Depth stratified sampling revealed that $M$. leidyi was mainly distributed in the upper $25 \mathrm{~m}$, with few records below $50 \mathrm{~m}$ (Table $\mathrm{S}_{1}$ ).

In September-October 2010, M. leidyi was observed at most stations in and outside Oslofjord, with abundances reaching 0.56 ind $\mathrm{m}^{-3}$ in the upper $50 \mathrm{~m}$ (Figure 2, Table $\mathrm{S}_{1}$ ).

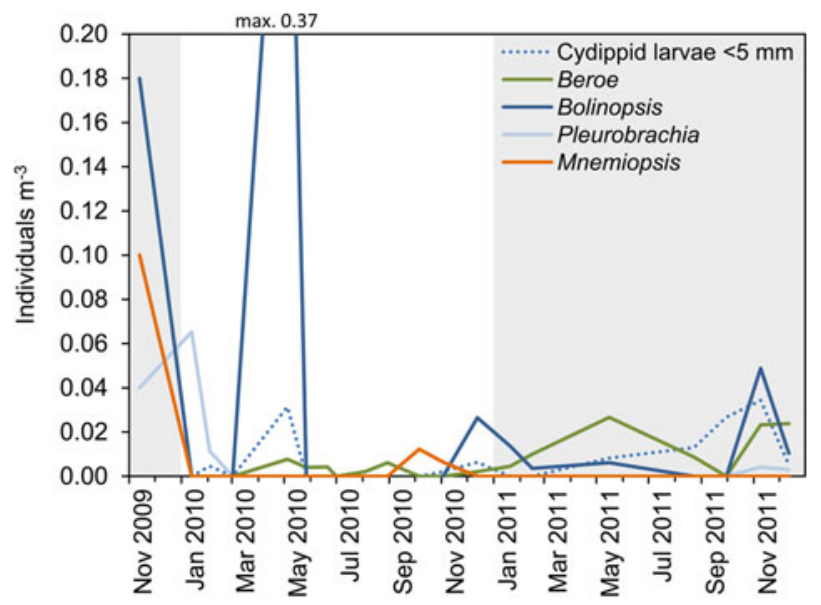

Fig. 3. Seasonal abundance of common ctenophores at Raunefjord. Average from stations 1 and $2, \sim$ monthly $\mathrm{WP}_{3}$ hauls from bottom to surface. 
In September 2014, M. leidyi was observed at both ends of the Torungen-Hirtshals transect, but not at the middle station (Figure 1, Table $\mathrm{S}_{1}$ ). The abundances were the highest recorded during our monitoring efforts - up to 1.96 ind $\mathrm{m}^{-3}$ in the upper $50 \mathrm{~m}$.

When considering the observed abundances in our data, it should be taken into account that the haul depths and the proportion of the sampled water column vary (Table $\mathrm{S}_{1}$ ). The calculated concentrations per cubic metre assume even distribution within the sampled layer; however, this is hardly realistic, as also shown by our depth stratified MOCNESS data.

\section{Beach seine bycatch}

Lobate ctenophore bycatch in beach seines was first noted in 2005, at a few stations. Abundant lobate ctenophores were caught in 2007-2010, followed by their disappearance from the beach seines in 2011-2013. In 2014, high abundances were again observed (Figure 4). It should be noted that not all lobate bycatch was identified to species, but the combination of its sudden appearance in 2005, the timing of the investigation during the Mnemiopsis leidyi peak season in the autumn (as opposed to Bolinopsis infundibulum, which peaks in the spring) and the available photographic evidence suggest that it is likely primarily $M$. leidyi.

\section{Environmental conditions}

According to the time series on temperature minima and maxima at the hydrographic stations, surface temperature should consistently reach an annual maximum sufficient for

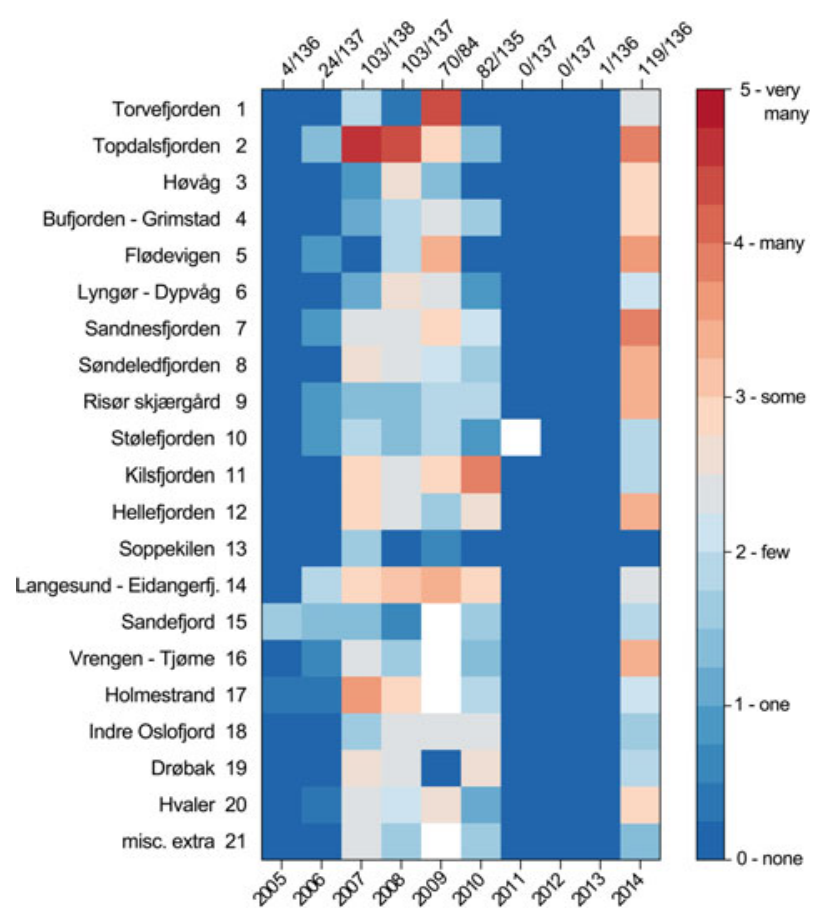

Fig. 4. Mean index of lobate ctenophore bycatch in beach seines from 21 areas along the Norwegian south coast, autumn 2005-2014 (for locations, see Figure 1). White fill indicates missing data. Upper $\mathrm{x}$-axis labels show number of sites with lobate ctenophores vs total number of sampled sites for the given year.
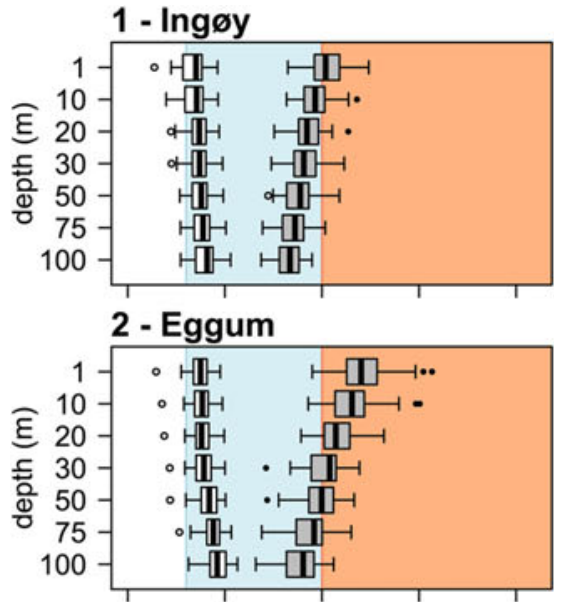

3 - Skrova

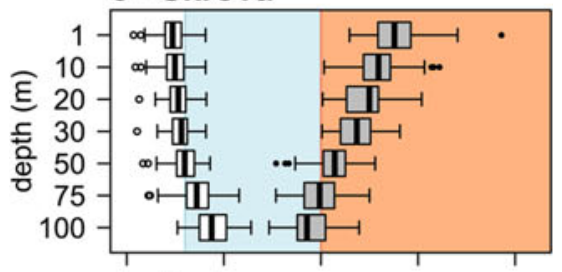

4 - Bud

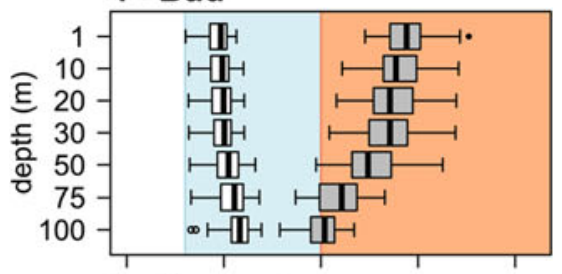

5 - Sognesjø

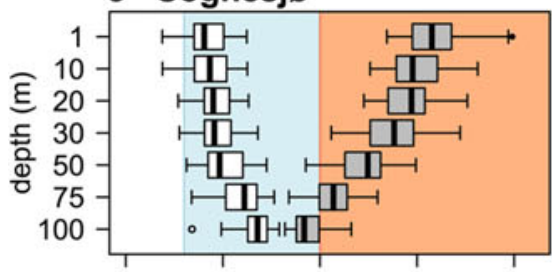

6 - Indre Utsira
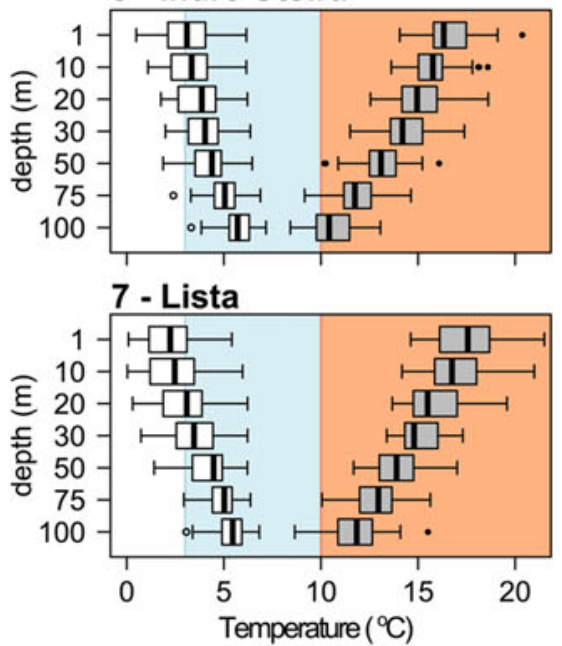

Fig. 5. Boxplots of time series of annual minimum (white) and maximum (grey) temperatures for past 40-80 years at seven hydrographical stations along the Norwegian coast (for locations, see Figure 1). The blue and orange backgrounds indicate conservative estimates of temperature ranges allowing Mnemiopsis leidyi survival $\left(>3^{\circ} \mathrm{C}\right)$ and reproduction $\left(>10^{\circ} \mathrm{C}\right)$, respectively. 
reproduction at least up to the level of Bud at $\sim 63^{\circ} \mathrm{N}$ (Figure 5). Below freezing temperatures were never observed in the time series, which should allow for the survival of Mnemiopsis leidyi at the salinities predominating along the Norwegian coast.

\section{Other observations}

Most observations from divers corresponded with the geographic range and timing of observations from net sampling and/or beach seine observations (data not shown). However, they also included the northernmost confirmed observation from outside Selva, Trondheimsfjord, in September 2008 (K. Telnes; http://www.seawater.no/fauna/ctenophora/images/ IMG2008_2828.jpg) as well as the only confirmed observation in 2013 from outside Stavern, Larviksfjord (S. Sarre; https:// www.flickr.com/photos/52065318@No3/10312589883)

(Figure 1).

\section{DISCUSSIDN}

\section{Environmental conditions}

Mnemiopsis leidyi is native along the West Atlantic coast, from Argentina in the south to New England in the North, with the highest abundances found in temperate latitudes on both hemispheres (Costello et al., 2012). It is a primarily neritic species, rarely found in large numbers in the less productive oceanic waters (Costello et al., 2012). The species exhibits morphological variation both in its native and introduced ranges, and the genus Mnemiopsis has previously been divided into several species based on morphology and distribution. Recent molecular studies support a single species, M. leidyi A. Agassiz, 1865, that exhibits various morphotypes related to environmental conditions (reviewed in Costello et al., 2012). Genetic studies suggest that while the southern European invaders stem from the Gulf of Mexico region, the invaders to northern Europe originate from the coast of New England (Reusch et al., 2010) and could thus be expected to be better adapted to the North East Atlantic climatic conditions.

Mnemiopsis leidyi tolerates a wide range of salinities and temperatures, $\sim 0-32{ }^{\circ} \mathrm{C}$ and $<2-39$ PSU (Purcell et al., 2001; Costello et al., 2012). Egg production of M. leidyi from Gullmarsfjorden, Sweden, increases with salinity (range 6-33), with the highest reproductive rates observed at salinities of 25 and 33 , and salinity $<_{10}$ compromising reproduction (Jaspers et al., 2011). Salinity is thus unlikely to be a limiting factor along the Norwegian coast, where the NCC has a salinity of 25-34.5 and fjords feature a varyingly brackish surface layer and more saline bottom water influenced by Atlantic water with salinity $>34.5-35$ (Sætre, 2007; Aure et al., 2007). At comparable salinities, M. leidyi is in its native range encountered at temperatures ranging from o to $>30^{\circ} \mathrm{C}$ (reviewed in Haraldsson et al., 2013). In Narragansett Bay, live M. leidyi have even been observed under ice in below freezing temperatures (Costello et al., 2006). Winter minimum temperatures at the hydrographical stations along the Norwegian coast were consistently higher when deeper in the water column (Figure 5), suggesting M. leidyi could also find refuge from cold temperatures by overwintering at depth. While this would suggest that winter temperatures are not the main factor limiting survival along the Norwegian coast, $M$. leidyi were nevertheless not to be found after the exceptionally cold winters of 2010 and 2011.

Summer water temperatures along the southern Norwegian coast are sufficient for $M$. leidyi reproduction, although temperatures may constrain the reproductive rates. The approximate lower temperature limit for successful egg production by $M$. leidyi is around $10-12^{\circ} \mathrm{C}$ (Costello et al., 2012; Lehtiniemi et al., 2012), but egg production is highly temperature dependent above this minimum requirement (Purcell et al., 2001). The annual maximum temperature along the Norwegian coast is consistently above $12^{\circ} \mathrm{C}$, at least to the level of Bud, with most years being notably warmer (Figure 5). Our ranges of minimum and maximum temperatures do not take into account the warming that has occurred during the long observation period over several decades, and are, therefore, conservative estimates of the current situation. Many of our M. leidyi observations are from temperatures that would be expected to restrict egg production (Table $\mathrm{S}_{1}$ ). The highest $M$. leidyi concentrations in Norway were recorded in 2014 and coincided with the warmest water temperatures during our study.

The seasonal monitoring from Raunefjord, on the west coast, shows $M$. leidyi occurring only late in the fall. Both their late appearance and the concurrent low temperatures imply that the M. leidyi were advected to the area with the coastal current, rather than produced locally. As our data only show autumnal snapshots from the Skagerrak area, it is not possible to say whether an actively reproducing population was present earlier in the summer, when water temperatures were higher, or whether these observations also reflect advection from a more favourable source area. A recent study modelling habitat suitability in the North Sea has identified Skagerrak as a high risk area for M. leidyi establishment due to relatively warm temperatures and high food availability (Collingridge et al., 2014).

\section{Biological interactions}

While temperature and salinity set the boundaries for survival and reproductive success of Mnemiopsis leidyi, biological interactions are important in controlling population size. Egg production in M. leidyi is sensitive to food availability (Reeve et al., 1989) and the species tolerates starvation relatively poorly (Anninsky et al., 2005; Costello et al., 2012). Relatively high prey abundances are, thus, a prerequisite for population expansion (Costello et al., 2012). Mnemiopsis leidyi is rarely found where mesozooplankton prey concentrations are below $3 \mathrm{mg} \mathrm{C} \mathrm{m}^{-3}$ (Kremer, 1994) and concentrations higher by an order of magnitude are needed for unlimited growth. In addition, larvae require microplankton prey concentrations of $>40 \mathrm{mg} \mathrm{C} \mathrm{m}^{-3}$ for growth (reviewed in Collingridge et al., 2014). According to a recent modelling study, food availability could limit winter survival in large parts of the North Sea (Collingridge et al., 2014). In comparison, the annual minimum concentration of mesozooplankton in coastal areas of Skagerrak and western Norway occurs in November-January, and varies between 0.3 and $2 \mathrm{mg}$ $\mathrm{C} \mathrm{m}{ }^{-3}$, assuming a carbon content of $50 \%$ dry weight $\mathrm{T}$. Falkenhaug, unpublished data). However, patches of higher

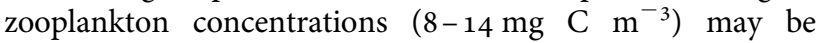
present in inner fjord areas during autumn and winter (Falkenhaug \& Dalpadado, 2014), making these areas 
potentially suitable for overwintering. Respiration demands of M. leidyi are also significantly correlated with temperature (Lilley et al., 2014) and would, thus, be relatively low in the cold Nordic waters.

The Norwegian coast has a rich gelatinous fauna (Hosia \& Bamstedt, 2007) and competition from native gelatinous predators could reduce $M$. leidyi numbers or prevent establishment (Riisgård et al., 2010). A superficially similar lobate, Bolinopsis infundibulum, is native along the entire Norwegian coast. It reproduces at lower temperatures than M. leidyi and its seasonal timing allows it to better utilize the high zooplankton abundances following the spring bloom. Bolinopsis infundibulum could also be better at exploiting low prey densities; studies from the Bahamas and the Aegean suggest that $M$. leidyi requires an order of magnitude for higher ambient prey concentrations than the co-occurring lobate Bolinopsis vitrea, and that the latter dominates in the less productive areas (Kremer et al., 1986; Shiganova et al., 2004).

Predation, particularly by gelatinous predators, can also regulate $M$. leidyi populations, with cascading effects on the pelagic ecosystem (reviewed in Costello et al., 2006; Purcell et al., 2001). The devastating effects of the M. leidyi invasions in the Ponto-Caspian were partly due to the initial lack of predators in these systems. In comparison, a host of native North-East Atlantic gelatinous predators capable of feeding on M. leidyi have been identified, including Beroe cucumis and Cyanea capillata, common in Norwegian waters, as well as the more rarely observed Beroe gracilis, Chrysaora hysoscella and Pelagia noctiluca (Hosia \& Titelman, 2011; Hosia et al., 2011; Tilves et al., 2012; Galil \& Gevili, 2013). In addition, M. leidyi's native West Atlantic predator Beroe ovata, sensu Mayer 1912, credited for reducing the M. leidyi populations of the Black Sea after its accidental introduction there in the late 1990s, has recently been observed for the first time in the Danish Straits adjacent to the North Sea (Shiganova et al., 2014).

On the other hand, intraguild predation by M. leidyi could have a negative impact on native gelatinous predators, both through competition for common prey and direct predation on juvenile stages. The ctenophore has been shown to prey on Beroe larvae in incubation experiments (Hosia et al., 2011) and high numbers of Aurelia aurita planulae have been found in $M$. leidyi stomachs from the Kiel Bight (Javidpour et al., 2009). This raises questions about whether the $M$. leidyi invasion could play a role in the diminishing A. aurita observations in the North Sea (Hosia et al., 2014).

The North European populations of $M$. leidyi also carry larvae of the parasitic sea-anemone Edwardsiella sp. (Selander et al., 2010). In our Norwegian samples, Edwardsiella larvae were seldom observed, but can, for example, be seen infesting the specimen photographed from Trondheimsfjord (http:// www.seawater.no/fauna/ctenophora/images/IMG2008_2828.jpg). In 2014, the infection rate in Flødevigen appears to be higher than in earlier years (T. Falkenhaug, personal observation). Edwardsiella lineata have been shown to reduce growth rates and, subsequently, reproductive output of infected M. leidyi in its native range (Bumann \& Puls, 1996).

\section{Source-sink dynamics}

Mnemiopsis leidyi exhibits pronounced source-sink dynamics with local extinctions at less favourable locations combined with repeated annual re-colonization from adjacent seed areas in both its native and introduced ranges (Purcell et al., 2001; Costello et al., 2006, 2012; Bolte et al., 2013). During the non-reproductive period, advective losses can result in the disappearance of $M$. leidyi from large areas (Costello et al., 2006, 2012). Successful overwintering takes place in regions with low water exchange, which allows the populations to persist over winter (Costello et al., 2006, 2012). These regions then serve as source populations for the annual reintroduction of $M$. leidyi to the sink areas.

Such dynamics are probably also pertinent to the Norwegian coast. Overwintering M. leidyi have been observed in southern areas of the North Sea (Van Ginderdeuren et al., 2012; van Walraven et al., 2013) as well as in the Bay of Seine on the south coast of the English Channel (Antajan et al., 2014). These regions with established populations can act as seed areas, with the cyclonic circulation in the North Sea and the NCC transporting ctenophores to and along the Norwegian coast. The decreasing amounts of $M$. leidyi observed towards the inner fjords along the Norwegian west coast in 2008 and the late appearance of the ctenophores in Raunefjord in 2010 would also agree with advection of the ctenophores with the coastal current. In addition to our observations from the south coast in 2014, there are also several unconfirmed $M$. leidyi observations from the vicinity of Bergen this year. Large numbers of $M$. leidyi together with Pleurobrachia pileus $(\sim 50 / 50,>3.5 \mathrm{~kg}$ combined) were also caught in a trawl from 20-40 m off the Norwegian coast, just south of Sognefjord, in mid-October 2014 (Figure 1), suggesting spreading of the ctenophores with the coastal current also this year (at $60.7967^{\circ} \mathrm{N} 3.7483^{\circ} \mathrm{E}$ on 15 October 2014, during an R/V G.O. Sars cruise by the Department of Biology, University of Bergen; H. Savolainen, personal communication). Transport time from the German Bight to the Skagerrak has been estimated to be on the order of 1-3 months (Kristensen, 1991). This transport is highly dependent on the wind regime and may vary between years (Heilmann et al., 1991), possibly contributing to the interannual differences in $M$. leidyi abundances in Norway, evident, for example, in the beach seine bycatch. Assuming a coastal current velocity of $\sim 0.5$ knots, a further month would be spent in reaching the vicinity of Bergen. Southern North Sea $M$. leidyi could also overwinter at an intermediate location en route (van der Molen et al., 2014), or periodic new inoculations could occur from further afield through ballast water transport.

Within its native range in Narragansett Bay, M. leidyi overwinter in shallow inshore retention areas (Costello et al., 2006; Beaulieu et al., 2013). Protected inner fjords or polls (offshoot of a fjord with a narrow entrance and a shallow sill) with limited water exchange could also provide a suitable habitat for the establishment of permanent populations in Norway. These habitats feature varyingly brackish water, higher summer temperatures than the open ocean and refuge from advective losses. While the upper layers of fjords are characterized by estuarine circulation transporting brackish water out of the fjord and, below it, coastal water into the fjord, water exchange below sill level is much reduced, facilitating the retention of plankton and formation of resident populations (Aksnes et al., 1989; Sørnes et al., 2007; Hosia \& Bamstedt, 2008). This kind of overwintering strategy is used by the lobate ctenophore Bolinopsis infundibulum in Malangen fjord, northern Norway (Falkenhaug, 1996). The 
ctenophore overwinters in extremely low concentrations deep in the innermost basin of the fjord, where advection is limited, as well as in a nearby semi-enclosed bay. These seed populations then give rise to a rapid increase in biomass in the spring.

Protected fjords could also provide a favourable habitat in the sense that $M$. leidyi tends to avoid turbulent waters, possibly due to the ambient fluid motion interfering with its feeding currents (Mianzan et al., 2010; Sutherland et al., 2014). In terms of food availability, mesozooplankton concentrations in inner Hardangerfjord are equivalent to $\sim 2-9.5 \mathrm{mg} \mathrm{C} \mathrm{m}^{-3}$ in the spring, with patches of $8-14 \mathrm{mg}$ $\mathrm{C} \mathrm{m}^{-3}$ found in autumn and winter (Falkenhaug \& Dalpadado, 2014). The predatory ctenophore Beroe cucumis is also known to inhabit fjord basins year round, potentially limiting the survival of overwintering lobates (Falkenhaug, 1996). Also in the current study, Beroe cucumis was observed more or less continuously in Raunefjord. As it is, the monitoring of ctenophores in Norway is insufficient for discovering M. leidyi populations potentially establishing in inner fjords, fjord basins or polls before they become noticeably abundant.

\section{CDNCLUSIDNS}

Even though temperature and salinity along the south-western Norwegian coast are within the limits for successful overwintering and reproduction by Mnemiopsis leidyi, populations are likely limited by advective losses, temperature constraints on reproductive rates and biological factors including limiting prey densities as well as intraguild competition and predation by native gelatinous predators. The highest M. leidyi abundances in the current study were observed in the Skagerrak area, which has also been identified as a high risk area for M. leidyi blooms (Collingridge et al., 2014). The populations in Norwegian waters probably exhibit source-sink dynamics, either with the southern North Sea - with its year-round populations acting as a source area - or, speculatively, by $M$. leidyi establishing overwintering seed populations in protected fjords or polls in southern Norway. Considering the high fecundity of $M$. leidyi and the cyclonic circulation in the North Sea, it seems highly likely that outbreaks along the south and west Norwegian coasts may be expected in future years, with favourable conditions or significant inflow from the southern North Sea. Higher water temperatures due to climate change could, in the future, enhance reproductive success and facilitate overwintering of $M$. leidyi in Norwegian waters. In $M$. leidyi's native range, spatiotemporal expansion due to a warming climate seems to have increased its potential for inflicting a negative impact on the plankton community (Beaulieu et al., 2013). Suggested future research includes the systematic monitoring of $M$. leidyi in Norwegian waters in order to identify environmental parameters influencing the interannual patterns of abundance, a focus on M. leidyi's overwintering ecology including identifying and monitoring potential overwintering habitats as well as the modelling of the potential source-sink dynamics at scales relevant to the Norwegian coast.

\section{Supplementary material and methods}

The supplementary material for this article can be found at http://www.journals.cambridge.org/MBD.

\section{ACKNDWLEDGEMENTS}

This work was supported by the Research Council of Norway (RCN) program HAVKYST (A.H. and T.F., project no. 190304), the ForBio Research School funding from RCN (A.H., project no. 210460) and the Norwegian Taxonomy Initiative (A.H., project no. 70184215). We wish to thank the crews of R/Vs Håkon Mosby, Hans Brattstrøm and G.M. Dannevig for help with sampling; Ø. Paulsen, M.J. Ohldieck and other participants in the beach seine project; J. Albretsen for help with hydrography and K. Telnes, S. Sarre and other UW photographers and divers for responding to our queries.

\section{REFERENCES}

Aksnes D.L., Aure J., Kaartvedt S., Magnesen T. and Richard J. (1989) Significance of advection for the carrying capacities of fjord populations. Marine Ecology Progress Series 50, 263-274.

Anninsky B.E., Finenko G.A., Abolmasova G.I., Hubareva E.S., Svetlichny L.S., Bat L. and Kideys A.E. (2005) Effect of starvation on the biochemical compositions and respiration rates of ctenophores Mnemiopsis leidyi and Beroe ovata in the Black Sea. Journal of the Marine Biological Association of the United Kingdom 85, 549-561.

Antajan E., Bastian T., Raud T., Brylinski J.-M., Hoffman S., Breton G., Cornille V., Delegrange A. and Vincent D. (2014) The invasive ctenophore Mnemiopsis leidyi A. Agassiz, 1865 along the English Channel and the North Sea French coasts: another introduction pathway in northern European waters? Aquatic Invasions 9, 167-173.

Aure J., Asplin L. and Sætre R. (2007) Coast/fjord water exchange. In Sætre R. (ed.) The Norwegian Coastal Current, Trondheim: Tapir Academic Press, pp. 115-124.

Beaulieu W.T., Costello J.H., Klein-Macphee G. and Sullivan B.K. (2013) Seasonality of the ctenophore Mnemiopsis leidyi in Narragansett Bay, Rhode Island. Journal of Plankton Research 35, 785-791.

Boersma M., Malzahn A.M., Greve W. and Javidpour J. (2007) The first occurrence of the ctenophore Mnemiopsis leidyi in the North Sea. Helgoland Marine Research 61, 153-155.

Bolte S., Fuentes V., Haslob H., Huwer B., Thibault-Botha D., Angel D., Galil B., Javidpour J., Moss A.G. and Reusch T.B.H. (2013) Population genetics of the invasive ctenophore Mnemiopsis leidyi in Europe reveal source-sink dynamics and secondary dispersal to the Mediterranean Sea. Marine Ecology Progress Series 485, 25-36.

Bumann D. and Puls G. (1996) Infestation with larvae of the sea anemone Edwardsia lineata affects nutrition and growth of the ctenophore Mnemiopsis leidyi. Parasitology 113, 123-128.

Collingridge K., van der Molen J. and Pitois S. (2014) Modelling risk areas in the North Sea for blooms of the invasive comb jelly Mnemiopsis leidyi A. Agassiz, 1865. Aquatic Invasions 9, 21-36.

Costello J.H., Bayha K.M., Mianzan H.W., Shiganova T.A. and Purcell J.E. (2012) Transitions of Mnemiopsis leidyi (Ctenophora: Lobata) from a native to an exotic species: a review. Hydrobiologia 690, 21-46.

Costello J.H., Gifford D.J., Van Keuren D. and Sullivan L.J. (2006) Seasonal refugia, shoreward thermal amplification, and metapopulation dynamics of the ctenophore Mnemiopsis leidyi in Narragansett Bay, Rhode Island. Limnology and Oceanography 51, 1819-1831.

Daskalov G.M., Grishin A.N., Rodionov S. and Mihneva V. (2007) Trophic cascades triggered by overfishing reveal possible mechanisms of ecosystem regime shifts. Proceedings of the National Academy of Sciences of the United States of America 104, 10518-10523. 
Durif C.M., Gjosaeter J. and Vollestad L.A. (2011) Influence of oceanic factors on Anguilla anguilla (L.) over the twentieth century in coastal habitats of the Skagerrak, southern Norway. Proceedings of the Royal Society B: Biological Sciences 278, 464-473.

Faasse M.A. and Bayha K.M. (2006) The ctenophore Mnemiopsis leidyi A. Agassiz 1865 in coastal waters of the Netherlands: an unrecognized invasion? Aquatic Invasions 1, 270-277.

Falkenhaug T. (1996) Distributional and seasonal patterns of ctenophores in Malangen, northern Norway. Marine Ecology Progress Series 140, $59-70$.

Falkenhaug T. and Dalpadado P. (2014) Diet composition and food selectivity of sprat (Sprattus sprattus) in Hardangerfjord, Norway. Marine Biology Research 10, 203-215.

Fromentin J.-M., Stenseth N.C., Gjøsæter J., Bjørnstad O.N., Falck W. and Johannessen T. (1997) Spatial patterns of the temporal dynamics of three gadoid species along the Norwegian Skagerrak coast. Marine Ecology Progress Series 155, 209-222.

Galil B.S. and Gevili R. (2013) A moveable feast: Beroe cucumis sensu Mayer, 1912 (Ctenophora; Beroida; Beroidae) preying on Mnemiopsis leidyi A. Agassiz, 1865 (Ctenophora; Lobata; Bolinopsidae) off the Mediterranean coast of Israel. BioInvasions Records 2, 191-194.

Ghabooli S., Shiganova T., Zhan A., Cristescu M., Eghtesadi-Araghi P. and MacIsaac H. (2011) Multiple introductions and invasion pathways for the invasive ctenophore Mnemiopsis leidyi in Eurasia. Biological Invasions 13, 679-690.

Granhag L., Møller L.F. and Hansson L.J. (2011) Size-specific clearance rates of the ctenophore Mnemiopsis leidyi based on in situ gut content analyses. Journal of Plankton Research 33, 1043-1052.

Hansson H.G. (2006) Ctenophores of the Baltic and adjacent seas - the invader Mnemiopsis is here! Aquatic Invasions 1, 295-298.

Haraldsson M., Jaspers C., Tiselius P., Aksnes D.L., Andersen T. and Titelman J. (2013) Environmental constraints of the invasive Mnemiopsis leidyi in Scandinavian waters. Limnology and Oceanography 58, 763-763.

Heilmann J.P., Olsen O.V. and Danielssen D.S. (1991) The potential of the Jutland coastal current as a transporter of nutrients to the Kattegat. International Council for the Exploration of the Sea (CM Documents), CM 1991/C:34, 20 pp.

Hosia A. and Bamstedt U. (2007) Seasonal changes in the gelatinous zooplankton community and hydromedusa abundances in Korsfjord and Fanafjord, western Norway. Marine Ecology Progress Series 351, $113-127$.

Hosia A. and Bamstedt U. (2008) Seasonal abundance and vertical distribution of siphonophores in western Norwegian fjords. Journal of Plankton Research 30, 951-962.

Hosia A., Falkenhaug T. and Naustvoll L.J. (2014) Trends in abundance and phenology of Aurelia aurita and Cyanea spp. at a Skagerrak location, 1992-2011. Marine Ecology Progress Series 498, 103-115.

Hosia A. and Titelman J. (2011) Intraguild predation between the native North Sea jellyfish Cyanea capillata and the invasive ctenophore Mnemiopsis leidyi. Journal of Plankton Research 33, 535-540.

Hosia A., Titelman J., Hansson L.J. and Haraldsson M. (2011) Interactions between native and alien ctenophores: Beroe gracilis and Mnemiopsis leidyi in Gullmarsfjorden. Marine Ecology Progress Series 422, 129-138.

Jaspers C., Møller L.F. and Kiørboe T. (2011) Salinity gradient of the Baltic Sea limits the reproduction and population expansion of the newly invaded comb jelly Mnemiopsis leidyi. PLoS ONE 6, e24065, doi: 10.1371/journal.pone.0024065.
Javidpour J., Molinero J.C., Peschutter J. and Sommer U. (2009) Seasonal changes and population dynamics of the ctenophore Mnemiopsis leidyi after its first year of invasion in the Kiel Fjord, Western Baltic Sea. Biological Invasions 11, 873-882.

Javidpour J., Sommer U. and Shiganova T. (2006) First record of Mnemiopsis leidyi A. Agassiz 1865 in the Baltic Sea. Aquatic Invasions 1, 299-302.

Kideys A.E. (2002) Fall and rise of the Black Sea ecosystem. Science 297, $1482-1484$.

Knowler D. (2005) Reassessing the costs of biological invasion: Mnemiopsis leidyi in the Black sea. Ecological Economics 52, 187-199.

Kremer P. (1994) Patterns of abundance for Mnemiopsis leidyi in US coastal waters: a comparative overview. ICES Journal of Marine Science 51, 347-354.

Kremer P., Reeve M.R. and Syms M.A. (1986) The nutritional ecology of the ctenophore Bolinopsis vitrea: comparisons with Mnemiopsis mccradyi from the same region. Journal of Plankton Research 8, 1197-1208.

Kristensen K.B. (1991) The Jutland Coastal Current. Series Paper, Vol. 53, Institute of Hydrodynamics and Hydraulic Engineering, Technical University of Denmark, Denmark.

Lehtiniemi M., Lehmann A., Javidpour J. and Myrberg K. (2012) Spreading and physico-biological reproduction limitations of the invasive American comb jelly Mnemiopsis leidyi in the Baltic Sea. Biological Invasions 14, 341-354.

Lilley M.K.S., Thibault-Botha D. and Lombard F. (2014) Respiration demands increase significantly with both temperature and mass in the invasive ctenophore Mnemiopsis leidyi. Journal of Plankton Research 36, 831-837.

Mianzan H.W., Martos P., Costello J.H. and Guerrero R.A. (2010) Avoidance of hydrodynamically mixed environments by Mnemiopsis leidyi (Ctenophora: Lobata) in open-sea populations from Patagonia, Argentina. Hydrobiologia 645, 113-124.

Oliveira O.M.P. (2007) The presence of the ctenophore Mnemiopsis leidyi in the Oslofjorden and considerations on the initial invasion pathways to the North and Baltic Seas. Aquatic Invasions 2, 185-189.

Purcell J.E., Shiganova T.A., Decker M.B. and Houde E.D. (2001) The ctenophore Mnemiopsis in native and exotic habitats: U.S. estuaries versus the Black Sea basin. Hydrobiologia 451, 145-176.

R Core Team (2013) R: a Language and environment for statistical computing. R Foundation for Statistical Computing: Vienna, Austria, ISBN 3-900051-07-o at http://www.R-project.org/

Reeve M.R., Syms M.A. and Kremer P. (1989) Growth dynamics of a ctenophore (Mnemiopsis) in relation to variable food supply. I. Carbon biomass, feeding, egg production, growth and assimilation efficiency. Journal of Plankton Research 11, 535-552.

Reusch T.B.H., Bolte S., Sparwel M., Moss A.G. and Javidpour J. (2010) Microsatellites reveal origin and genetic diversity of Eurasian invasions by one of the world's most notorious marine invader, Mnemiopsis leidyi (Ctenophora). Molecular Ecology 19, 2690-2699.

Riisgård H.U., Barth-Jensen C. and Madsen C.V. (2010) High abundance of the jellyfish Aurelia aurita excludes the invasive ctenophore Mnemiopsis leidyi to establish in a shallow cove (Kertinge Nor, Denmark). Aquatic Invasions 5, 347-356.

Roohi A., Kideys A.E., Sajjadi A., Hashemian A., Pourgholam R., Fazli H., Khanari A.G. and Eker-Develi E. (2010) Changes in biodiversity of phytoplankton, zooplankton, fishes and macrobenthos in the Southern Caspian Sea after the invasion of the ctenophore Mnemiopsis leidyi. Biological Invasions 12, 2343-2361. 
Selander E., Møller L., Sundberg P. and Tiselius P. (2010) Parasitic anemone infects the invasive ctenophore Mnemiopsis leidyi in the North East Atlantic. Biological Invasions 12, 1003-1009.

Shiganova T.A., Christou E.D., Bulgakova J.V., Sioukou-Frangou I., Zervoudaki S. and Siapatis A. (2004) Distribution and biology of Mnemiopsis leidyi in the Northern Aegean Sea, and comparisons with the indigenous Bolinopsis vitrea. In Dumont H., Shiganova T. and Niermann U. (eds) Aquatic invasions in the Black, Caspian and Mediterranean Seas. The ctenophores Mnemiopsis leidyi and Beroe in the Ponto-Caspian and other aquatic invasions. Netherlands: Springer, pp. $113-135$.

Shiganova T.A., Riisgård H.U., Ghabooli S. and Tendal O.S. (2014) First report on Beroe ovata in an unusual mixture of ctenophores in the Great Belt (Denmark). Aquatic Invasions 9, 111-116.

Sutherland K.R., Costello J.H., Colin S.P. and Dabiri J.O. (2014) Ambient fluid motions influence swimming and feeding by the ctenophore Mnemiopsis leidyi. Journal of Plankton Research 36, 1310- 1322.

Sætre R. (2007) Properties of coastal water masses. In Sætre R. (ed.) The Norwegian Coastal Current. Trondheim: Tapir Academic Press, pp. $59-72$.

Sætre R. and Aure J. (2007) Characteristic circulation features. In Sætre R. (ed.) The Norwegian Coastal Current. Trondheim: Tapir Academic Press, pp. 99-114.

Sørnes T.A., Aksnes D.L., Bamstedt U. and Youngbluth M.J. (2007) Causes for mass occurrences of the jellyfish Periphylla periphylla: a hypothesis that involves optically conditioned retention. Journal of Plankton Research 29, 157-167.

Tendal O.S., Jensen K.R. and Riisgård H.U. (2007) Invasive ctenophore Mnemiopsis leidyi widely distributed in Danish waters. Aquatic Invasions 2, 455-460.
Tilves U., Purcell J.E., Marambio M., Canepa A., Olariaga A. and Fuentes V. (2012) Predation by the scyphozoan Pelagia noctiluca on Mnemiopsis leidyi ctenophores in the NW Mediterranean Sea. Journal of Plankton Research 35, 218-224.

van der Molen J., van Beek J., Augustine S., Vansteenbrugge L., van Walraven L., Langenberg V., van der Veer H.W., Hostens K., Pitois S. and Robbens J. (2014) Modelling survival and connectivity of Mnemiopsis leidyi in the southern North Sea and Scheldt estuaries. Ocean Science Discussion 11, 1561-1611.

Van Ginderdeuren K., Hostens K., Hoffman S., Vansteenbrugge L., Soenen K., De Blauwe H., Robbens J. and Vincx M. (2012) Distribution of the invasive ctenophore Mnemiopsis leidyi in the Belgian part of the North Sea. Aquatic Invasions 7, 163-169.

van Walraven L., Langenberg V.T. and van der Veer H.W. (2013) Seasonal occurrence of the invasive ctenophore Mnemiopsis leidyi in the western Dutch Wadden Sea. Journal of Sea Research 82, 86-92.

and

Wiebe P.H., Morton A.W., Bradley A.M., Backus R.H., Craddock J.E., Barber V., Cowles T.J. and Flierl G.R. (1985) New developments in the MOCNESS, an apparatus for sampling zooplankton and micronekton. Marine Biology 87, 313-323.

\section{Correspondence should be addressed to:}

A. Hosia

The Natural History Collections

University Museum of Bergen

University of Bergen

P.O. Box 7800

NO-5020 Bergen, Norway

emails: aino.hosia@um.uib.no, aino.hosia@gmail.com 